\title{
Re: Errors in the NOF meta-analysis of calcium and vitamin D supplements
}

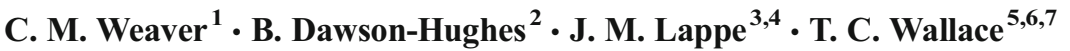

Received: 19 January 2016 / Accepted: 4 February 2016 / Published online: 18 March 2016

(C) The Author(s) 2016. This article is published with open access at Springerlink.com

\section{Dear Editor,}

The manuscript entitled "Calcium plus vitamin D supplementation and risk of fractures: an updated meta-analysis from the National Osteoporosis Foundation [1]" sought to update a former AHRQ evidence report [2]. The study was commissioned by the NOF to inform the organization, since a significant controversy exists regarding the effectiveness of supplemental calcium and vitamin D to prevent fractures. We chose to use the per protocol analyses data across studies to be consistent with the two former AHRQ evidence reports [2, 3] and to assess the actual effect of supplementation among individuals who were adherent throughout the duration of various

T. C. Wallace

taylor.wallace@nof.org

C. M. Weaver

weavercm@purdue.edu

B. Dawson-Hughes

bess.dawson-hughes@tufts.edu

J. M. Lappe

joanlappe@creighton.edu

1 Department of Nutrition Science, Women's Global Health Institute, Purdue University, West Lafayette, IN, USA

2 Jean Mayer USDA Human Nutrition Research Center on Aging, Bone Metabolism Laboratory, Tufts University, Boston, MA, USA

3 School of Nursing, Creighton University, Omaha, NE, USA

4 School of Medicine, Creighton University, Omaha, NE, USA

5 National Osteoporosis Foundation, Washington, DC, USA

6 Department of Nutrition and Food Studies, George Mason University, Fairfax, VA, USA

7 National Osteoporosis Foundation, 251 18th Street S. Suite 630, Arlington, VA 22202, USA studies included in the meta-analysis. It is challenging for a public-health organization to formulate accurate guidance solely from intention to treat analyses, where half of the population in some cases either dropped out or were not adherent by the end of the study. In both former AHRQ evidence reports $[2,3]$, adherence to the interventions were considered as part of the risk of bias assessment and analysis as adherence was important to estimate the actual doses received by the study participants for the purpose of deriving dietary reference intake (DRI) values; we chose for the same reason to continue this type of analysis. Though others may disagree with the decision to use per protocol analysis, alteration of the number of fractures among the studies present in Table 1 of Weaver et al. (2016) [1] and/or substitution with intention to treat analyses data does not influence the pooled relative risk or outcomes of the NOF meta-analysis. It is standard protocol for bodies such as the AHRQ to exclude studies in a nonEnglish language; it is unclear from the English abstract if the study [4] mentioned by Bolland and colleagues in their letter was designed to assess fracture outcomes. It also is unclear if the participants in the latter Chapuy et al. (1994) onepage narrative manuscript [5] were still randomized to the original study protocol (a large number of individuals are no longer present in the study). Since both studies by Chapuy and others show similar beneficial effects of supplemental calcium and vitamin D, it is unlikely that substitution of the Chapuy et al. (1992) [6] data with the Chapuy et al. (1994) [5] data will affect the pooled relative risk and/or outcomes of the NOF meta-analysis.

The NOF utilized (and continues to apply) rigorous basic elements of process when accepting commercial support. This process is modeled based on recommendations from the 2009 US Institute of Medicine (IOM) report on Conflict of Interest in Medical Research, Education, and Practice [7], as well as the processes of the US Preventive Services Task Force [8] and 
ACCME Standards for Commercial Support [9]. Furthermore, it is the internal process of the NOF that all contracted universities or consulting groups and expert volunteers serving as authors on any particular manuscript be blinded of the funding source until the manuscript is submitted for publication. The NOF is willing to share all documented communications with funding organizations for any of its activities. Data from the NOF meta-analysis [1] are publically available.

\section{Compliance with ethical standards}

Conflicts of interest Authors have declared all conflicts of interest in the original manuscript (DOI: 10.1007/s00198-015-3386-5).

Funding Funding sources for the original analyses (DOI: 10.1007/ s00198-015-3386-5) have been previously declared in the manuscript. The authors have not received additional funding or compensation for developing this response.

Open Access This article is distributed under the terms of the Creative Commons Attribution-NonCommercial 4.0 International License (http:// creativecommons.org/licenses/by-nc/4.0/), which permits any noncommercial use, distribution, and reproduction in any medium, provided you give appropriate credit to the original author(s) and the source, provide a link to the Creative Commons license, and indicate if changes were made.

\section{References}

1. Weaver CM, Alexander DD, Boushey CJ, Dawson-Hughes B, Lappe JM, LeBoff MS, Liu S, Looker AC, Wallace TC, Wang DD (2016)
Calcium plus vitamin D supplementation and risk of fractures: an updated meta-analysis from the National Osteoporosis Foundation. Osteoporos Int 27(1):367-376. doi:10.1007/s00198-015-3386-5

2. Chung M, Lee J, Terasawa T, Lau J, Trikalinos T (2011) Vitamin D with or without calcium supplementation for prevention of cancer and fractures: an updated meta-analysis for the U.S. Preventive Services Task Force. Ann Intern Med 155:827-838

3. Chung M, Balk EM, Brendel M, Ip S, Lau J, Lee J, Lichtenstein A, Patel K, Raman G, Tatsioni A, Terasawa T, Trikalinos T. 2009. Vitamin D and calcium: a systematic review of health outcomes, Evidence Report No. 183. (prepared by the Tufts Evidence-based Practice Center under contract HHSA 290-2007-10055-I) AHRQ Publication No. 09-E105. Rockville, MD: Agency for Healthcare Research and Quality. Accessed at www.ahrq.gov/downloads/pub/ evidence/pdf/vitadcal/.pdf on 21 December 2015.

4. Lopez-Torres Hidalgo J, Grupo A (2014) Effect of calcium and vitamin D in the reduction of falls in the elderly: a randomized trial vs. placebo. Med Clin (Barc) 142:95-102

5. Chapuy MC, Arlot ME, Delmas PD, Meunier PJ (1994) Effect of calcium and cholecalciferol treatment for three years on hip fractures in elderly women. BMJ 308:1081-1082

6. Chapuy MC, Arlot ME, Duboeue F, Brun J, Crouzet B, Arnaud S, Delmas PD, Meunier PJ (1992) Vitamin D3 and calcium to prevent hip fractures in elderly women. N Engl J Med 327:1637-1642

7. IOM (Institute of Medicine) (2009) Conflict of interest in medical research, education, and practice. The National Academies Press, Washington

8. U.S. Agency for Healthcare Research \& Quality. U.S. Preventive Services Task Force Procedure Manual. AHRQ Publication No. 08-05118-EF. July 2008. Accessed on February 24, 2014. Available from: http://www.uspreventiveservicestaskforce.org/Page/ Name/methods-and-processes.

9. Accreditation Council for Continuing Medical Education. Standards for Commercial Support: Standards to Ensure Independence in CME Activities. Accessed on February 24, 2014. Available from: http:// www.accme.org/requirements/accreditation-requirements-cmeproviders/standards-for-commercial-support. 